\title{
Transição Paradigmática na Educação Médica: Um Olhar Construtivista Dirigido à Aprendizagem Baseada em Problemas
}

\author{
Paradigm Shifts in Medical Education: a \\ Constructivist View of Problem-Based Learning
}

\author{
Pedro Henrique Netto Cezar \\ Francisco Tavares Guimarães ${ }^{I}$ \\ Andréia Patrícia Gomes ${ }^{I I}$ \\ Giselle Rôças ${ }^{I I I}$ \\ Rodrigo Siqueira-Batista ${ }^{I V}$
}

\section{PALAVRAS-CHAVE \\ - Aprendizagem Baseada em Problemas. \\ - Educação Médica. \\ - Metodologia.}

\section{KEY-WORDS}

- Problem-Based Learning.

- Medical Education.

- Methodology.

Artigo recebido em: 04/01/2009

Reecaminhado em: 19/09/2009

Aprovado em: 15/10/2009
REVISTA BRASILEIRA DE EDUCAÇÃO MÉDICA

\begin{abstract}
RESUMO
A necessidade de mudança no projeto político-pedagógico das escolas médicas vem sendo discutida, especialmente, em resposta a amadurecimento da reflexão acerca do perfil do egresso desejado. Reconhece-se que o ensino médico tradicional - centrado, prioritariamente, na transmissão de conhecimentos - tem levado à formação de profissionais despreparados para responder aos agravos à saúde mais encontrados na população. Para tentar mudar esse panorama, vêm sendo privilegiadas, a partir das Diretrizes Curriculares Nacionais do Curso de Graduação em Medicina do Ministério da Educação (MEC), as metodologias ativas de ensino-aprendizagem, entre as quais se destaca a Aprendizagem Baseada em Problemas (ABP), que permite maior participação do estudante na construção do conhecimento. Tal encaminhamento é realizado a partir da inclusão do graduando na comunidade desde os primeiros períodos do curso médico, promovendo a contextualização dos constructos teóricos adquiridos por meio de buscas individuais e do compartilhamento do conhecimento. Desta forma, cria-se uma parceria entre instituições de ensino superior, serviços de saúde e a comunidade, a partir da qual se espera formar médicos com uma visão integral do ser humano, comprometidos com a sociedade.
\end{abstract}

\section{ABSTRACT}

The need for changes in teaching and curricular policy in medical schools has been widely discussed, particularly in response to on-going reflection on the expected profile of medical school graduates. It has been acknowledged that traditional medical training, focused primarily on the transmission of knowledge, has produced graduates that are unprepared to respond to the population's most common health problems. In an attempt to change this situation in Brazil, active teaching-learning methodologies have been prioritized, based on the National Curricular Guidelines for Undergraduate Medical Education issued by the Ministry of Education. Such methodologies feature problem-based learning (PBL), which allows greater student participation in knowledge-building. This approach is developed by sending undergraduates into the community in their early years of medical school, thereby fostering the framing of theoretical constructs acquired through individual searches and knowledge-sharing. Thus, a partnership is created between institutions of higher learning, health services, and the community, the aim of which is to train physicians with a comprehensive view of human beings and a strong commitment to society.

${ }^{I}$ Centro Universitário Serra dos Órgãos, Teresópolis, RJ, Brasil; Instituto Federal de Educação, Ciência e Tecnologia do Rio de Janeiro, Nilópolis, RJ, Brasil.

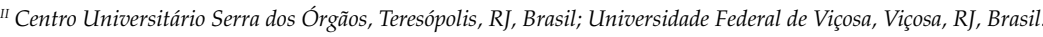

III Instituto Federal de Educação, Ciência e Tecnologia do Rio de Janeiro, Nilópolis, RJ, Brasil.

${ }^{I V}$ Centro Universitário Serra dos Órgãos, Teresópolis, RJ, Brasil; Instituto Federal de Educação, Ciência e Tecnologia do Rio de Janeiro, Nilópolis, RI, Brasil; Universidade Federal de Viçosa, Viçosa, RJ, Brasil. 


\section{INTRODUÇÃO}

O educando precisa assumir-se como tal, mas, assumir-se como educando significa reconhecer-se como sujeito que é capaz de conhecer e que quer conhecer em relação com outro sujeito igualmente capaz de conhecer, o educador e, entre os dois, possibilitando a tarefa de ambos, o objeto de conhecimento.

Paulo Freire

O ensino médico, nas últimas décadas, vem passando por um processo de ampla rediscussão, com o objetivo de formar um profissional com mais possibilidades de agir na resolução dos problemas de saúde dos indivíduos e da coletividade ${ }^{1-4}$. Neste âmbito, pode se destacar que o modelo de ensino tradicional, pautado na transmissão, no qual o aluno se limita a memorizar conteúdos ministrados, não possibilita, em geral, a formação de um egresso com tal perfil, pois reduz as possibilidades de o discente construir ativamente seu conhecimento ${ }^{2}$. Ao contrário, tais modelos concorrem para que o estudante se torne dependente do docente na aquisição de saberes e mantenha uma postura quase sempre passiva. Além disso, tal modelo não privilegia um contato maior com a comunidade, o que seria importantíssimo para contextualizar, em ação, os construtos teóricos agregados ${ }^{5}$ :

A prática é o eixo estruturante a partir do qual se estabelece o confronto experiencial com a realidade e se propicia a reflexão e a construção de saberes para o desenvolvimento profissional. Assim é, na ação, no desempenho frente a novas situações, que o profissional pode utilizar conhecimentos e habilidades ressignificados por meio do conjunto de seus valores pessoais. (p.17)

Dessa maneira, torna-se premente uma abordagem ampliada e integrada dos currículos, priorizando a formação de competências e o estímulo à utilização de metodologias ativas de aprendizagem, criando profissionais com ampla visão do homem ${ }^{6}$. Com isso, as instituições de ensino superior adquirem o compromisso com as necessidades da sociedade, particularmente na defesa da saúde como um direito e na garantia da universalização e da integralidade do cuidado à saúde, constituindo princípios de ação e estruturação do Sistema Único de Saúde, o SUS7.

As metodologias ativas se caracterizam por colocar o estudante no centro do processo de ensino-aprendizagem, tornando-o construtor do seu próprio conhecimento por meio de um currículo que agrega as diferentes disciplinas, permitindo que ele desenvolva um olhar amplo acerca do ser humano, nas suas relações com a sociedade e com o ambiente ${ }^{8}$. Exemplos destas metodologias são a Problematização e a Aprendizagem Baseada em Problemas (ABP), esta última a ser desenvolvida no presente artigo.

Neste movimento, o Ministério da Educação (MEC), ao divulgar as Diretrizes Curriculares Nacionais do Curso de Graduação em Medicina (DCN) ${ }^{1}$, em 2001, ressaltou a importância de adotar metodologias ativas de ensino, centradas na figura do estudante construtor do seu conhecimento, levandoo a desenvolver postura humanística e ética, voltada para a atenção ao enfermo/usuário. Partindo desses pressupostos, o MEC - juntamente com o Ministério da Saúde e a Organização Pan-Americana de Saúde - promoveu a criação do Programa de Incentivo às Mudanças Curriculares na Educação Médica (Promed), em dezembro de 2002. Este programa forneceu ajuda financeira às instituições de ensino médico dispostas a desencadear transformações no ensino de Medicina. Atualmente, tal iniciativa foi ampliada para o Programa Nacional de Reorientação da Formação Profissional em Saúde (Pró-Saúde), incluindo os cursos de graduação em Enfermagem e em Odontologia, que também incorporariam tal política pedagógica. Assim, ao concluírem sua formação, médicos, dentistas e enfermeiros estariam mais aptos a entender $\mathrm{a}-\mathrm{e}$ atuar na - realidade do País ${ }^{4,9,10}$.

Quanto à aquisição dos conhecimentos necessários à prática profissional, pode se reconhecer que a necessidade de mudar o processo político-pedagógico do curso médico se faz presente, pois os estudantes encontram grande dificuldade de correlacionar o exagerado volume de informações teóricas recebidas com a realidade das pessoas que frequentam os serviços de saúde. Isto remete à necessidade de refletir sobre os procedimentos atinentes à educação ${ }^{11}$ :

Educar não é somente transmitir ou transferir conhecimentos de uma pessoa para outra. Educar é, antes de tudo, contribuir para pensar bem, isto é, estabelecer relações de ajuda que possibilitem o surgimento de hábitos do pensamento, sentimentos e ações. (p. 10)

O estabelecimento de relações é um dos pressupostos para elaborar currículos integrados, que requerem articulação entre teoria e prática - e entre as distintas áreas do saber num processo flexível e multiprofissional, que leva em conta os saberes, as necessidades individuais de aprendizagem e os problemas da realidade - ou seja, os movimentos de acordo com os quais se constrói o conhecimento ${ }^{12}$ : 
A concepção construtivista visa criar condições adequadas para que os esquemas de conhecimento, inevitavelmente construídos pelos estudantes, sejam os mais ricos e corretos possíveis. (p. 54)

Com base nestas considerações, o presente ensaio tem por objetivo analisar, de forma crítica e reflexiva, a transição paradigmática — de base construtivista — da educação médica, avaliando como a introdução das novas metodologias ativas pode tornar o aprendizado mais dinâmico e integrado, tendo em conta as necessidades de saúde da população.

\section{MÉTODOS}

A investigação foi conduzida a partir da revisão crítica da literatura. Foram consultados textos, livros e artigos - buscados nas bases BVS (Biblioteca Virtual em Saúde), Pubmed (U.S. National Library of Medicine) e Scielo (Scientific Eletronic Library Online) - que discutem o construtivismo no ensino e na prática médica, privilegiando o aluno como centro do aprendizado. A partir dos manuscritos obtidos, construiu-se uma reflexão histórica sobre a implantação da $\mathrm{ABP}$ na educação médica, focando seus objetivos, sua aplicabilidade e como ela pode determinar uma participação maior do aluno na construção do seu conhecimento.

\section{RESULTADOS E DISCUSSÃO}

Os escritos de Paulo Freire ${ }^{2}$ ratificam a participação essencial dos conhecimentos prévios dos alunos nos processos de ensino-aprendizagem, contextualizando a educação na realidade das comunidades e vivências, e reconhecendo que o "educador precisa estar à frente de seu tempo". Ou seja, é imprescindível uma constante revisão e atualização das práticas pedagógicas, a fim de se obter o aprimoramento da formação, incluindo os diferentes partícipes dos processos de construção do conhecimento: professor, aluno e instituição de ensino ${ }^{13}$. Assim, é necessário que o estudante crie relações sociais importantes com seu professor e com os cenários de aprendizagem que frequenta, tornando mais efetiva a construção de conhecimentos.

Afins a tais propostas teóricas são as metodologias ativas, que vêm sendo empregadas nos cursos de graduação em Medicina desde 1969, consubstanciadas na ABP. Os cursos pioneiros foram implantados na Universidade de McMaster, no Canadá, e na Universidade de Maastricht, na Holanda, sendo posteriormente difundidas essas metodologias em países da Ásia, África e América Latina ${ }^{14}$. No Brasil, algumas escolas médicas vêm adotando a ABP, sendo a Faculdade de Medicina de Marília (Famema) e a Universidade Estadual de Londrina
(UEL) duas pioneiras no processo. No Estado do Rio de Janeiro, o Curso de Graduação em Medicina da Fundação Educacional Serra dos Órgãos (Feso) - atual Centro Universitário Serra dos Órgãos (Unifeso) - foi pioneiro na adoção da dinâmica da ABP, em $2005^{15,16}$

A ABP torna o discente um agente potencial de transformação social, capaz de detectar problemas e de criar soluções adequadas com base nos conteúdos teóricos trabalhados em sessões de tutoria. Importante também é o contato, desde os primeiros períodos, estabelecido entre os estudantes e a comunidade, por meio da inserção nas unidades básicas de saúde, permitindo contextualizar a teoria na prática vivenciada. Neste movimento, têm sido descritas mudanças na postura do aprendiz, que passa a ter um papel ativo no aprendizado, deixando de ser simples ouvinte e receptor das informações ${ }^{6}$. Para Bordenave e Pereira ${ }^{17}$ e Ferreira ${ }^{10}$, o discente aprende a aprender e é levado a entender o problema não apenas em suas características, mas também com relação aos princípios teóricos que o explicam.

Atualmente, o volume de informações disponíveis é de grande monta, o que torna impossível apreender todos os conteúdos considerados importantes pelos professores, sendo muitos deles jamais utilizáveis na vida profissional ${ }^{16}$. Logo, uma forma de aprendizado com ênfase na teoria não permite a atualização em tempo real, e a formação do profissional se torna deficiente. Daí a importância de um currículo integrado, de modo a estimular o aprendizado simultâneo de diversas habilidades que serão indispensáveis na vida prática ${ }^{8}$, além de permitir maior aproximação aluno-professor, o que também contribui muito para enriquecer o aprendizado ${ }^{18,19}$ :

O valor de um projeto educacional está na capacidade de proporcionar aos estudantes experiências (atividades educacionais) que produzam um desequilíbrio no seu conjunto de conhecimentos (previamente organizado) e uma modificação desse esquema (revisão, construção, enriquecimento $)^{20}$. (p. 7)

A ABP trabalha situações-problema que devem ser o mais possível aproximadas de situações vivenciadas na prática e, além disso, capazes de contemplar várias áreas do conhecimento médico, ocorrendo, dessa forma, a interação/integração entre as disciplinas. Os problemas devem ser construídos para alcançar objetivos educacionais predeterminados, a serem discutidos pelos alunos em sessão tutorial, após busca individual ${ }^{21}$.

Sakai e Lima ${ }^{22}$ mostram as características indispensáveis que uma situação-problema deve apresentar para ser correta- 
mente aplicada: ser concisa; consistir numa descrição neutra do fenômeno para o qual se busca uma explicação no grupo tutorial; ser formulada em termos concretos; ser isenta de distrações; dirigir o aprendizado a um número limitado de itens; dirigir-se apenas a itens que possam ter alguma explicação baseada nas experiências prévias dos alunos.

Tais situações devem ser criadas por uma equipe multidisciplinar de professores, de modo a contemplar diferentes aspectos do processo saúde-doença pertinentes ao ser humano, perpassando questões biológicas, psíquicas, éticas, socioeconômicas, históricas e ecológicas ${ }^{23,24}$. O processamento da situação-problema se dá no âmbito da sessão tutorial, quando os estudantes estão reunidos em pequenos grupos (entre oito e dez discentes), sob a responsabilidade de um professor tutor, que atua como facilitador dos processos ensino-aprendizagem, auxiliando no alcance dos objetivos traçados para cada situação-problema ${ }^{25}$. Vale ressaltar que entre as atribuições do tutor não consta ministrar aulas teóricas, como no método tradicional; ao contrário, ele deve estimular os aprendizes a eleger os pontos mais relevantes de cada situação-problema, que serão objeto de busca individual.

O processo tutorial é realizado a partir de determinados passos cuja estrutura e ordenação variam de autor para autor. Para Komatsu ${ }^{20}$, haveria sete passos: leitura da situação-problema com os estudantes, explicando-se termos desconhecidos; identificação pelos discentes dos aspectos principais envolvidos na situação (brain storm), o que é conseguido levando em conta as experiências e o conteúdo teórico de cada um; levantamento pelos aprendizes das questões de aprendizado a serem pesquisadas na busca individual; estudo individual com o emprego de livros, periódicos e outros recursos; discussão pelos estudantes na sessão tutorial seguinte, na qual as buscas com suas devidas referências são apresentadas por cada um e socializadas com o grupo, havendo a construção coletiva do conhecimento; respostas às questões de aprendizado escolhidas previamente; avaliação por parte dos discentes, que se autoavaliam, avaliam o grupo e o tutor; e avaliação por parte do tutor, que se autoavalia, avalia os estudantes e o grupo.

As atividades de tutoria contribuem para a construção do conhecimento cognitivo, sendo complementadas pelas atividades realizadas em laboratórios especializados. Nestes, um professor instrutor é encarregado de conduzir os processos pedagógicos que muito contribuirão para a prática profissional, sempre vinculada aos problemas estudados. Geralmente, tem-se o laboratório morfofuncional, onde são trabalhadas peças anatômicas, lâminas de anatomia patológica e lâminas de histologia, alcançando-se fundamentos de morfologia, fisiologia, fisiopatologia e anatomia patológica, tendo o aprendiz noção estrutural do indivíduo; e o laboratório de habilidades (LH), onde são executadas práticas de relevância para a parte assistencial.

Vale ressaltar que o primeiro LH foi construído na Universidade de Maastricht. Posteriormente, seu modelo foi aplicado nos países que adotaram a ABP, inclusive o Brasil, sendo a UEL a pioneira em sua instalação, em $1998^{26}$. De modo geral, quatro modelos de habilidades são trabalhados nesses laboratórios ${ }^{26}$ :

- Habilidades de semiologia: treinamento e capacitação para a realização de anamnese, exame físico, formulação de hipóteses diagnósticas e raciocínio clínico;

- Habilidades em procedimentos médicos: treinamento e capacitação em procedimentos médicos de média e baixa complexidade na sua execução, com fins terapêuticos ou de cuidado com o paciente: técnicas de curativos, imobilizações, injeções, suturas, cateterismo vesical, obtenção de acesso venoso, ressucitação cardiopulmonar e outros;

- Habilidades em laboratório clínico: treinamento e capacitação na realização de exames laboratoriais de baixa complexidade, bem como interpretação dos resultados dos exames utilizados na atenção à saúde;

- Habilidades de comunicação; desenvolver no estudante adequada relação médico-paciente, por meio do aprimoramento das técnicas de comunicação interpessoal, além de permitir o entendimento das reações apresentadas pelos pacientes com relação às doenças e de sua maneira de lidar com elas.

Além dos laboratórios de habilidades e morfofuncional, outro cenário de aprendizagem importante são as unidades básicas de saúde, nas quais os discentes são inseridos habitualmente logo no primeiro período do curso. Os estudantes podem acompanhar os agentes comunitários em visitas às microáreas da comunidade, onde começam a tomar contato com toda a problemática socioeconômica e sanitária enfrentada por essas populações. São também levados às visitas domiciliares, nas quais podem acompanhar determinada família. A inserção nas comunidades desde os primeiros períodos permite ao estudante criar consciência crítica sobre as condições de saúde do País, desenvolver um processo de humanização nas suas relações sociais e, principalmente, sentir-se responsável por dar sua contribuição para reverter essa situação.

Nesta perspectiva, busca-se a todo instante uma estreita relação entre o que é aprendido na teoria e na prática sem priorizar a sala de aula, como no modelo tradicional. Essa parceria entre as instituições de ensino, os serviços de saúde e a comunidade é vital para fazer valer as diretrizes e os princípios do SUS (equidade, universalidade, integralidade), concretizados nas políticas públicas de saúde ${ }^{7}$. O hospital, como cenário de 
prática, é utilizado ao longo do curso, sendo maior sua importância no período do internato.

Além do professor tutor e do instrutor, completam o corpo docente envolvido nos processos de ABP o professor conferencista, encarregado de ministrar palestras sobre temas mais amplos, relacionados às situações-problema, e o professor consultor, geralmente um especialista procurado para resolver dúvidas surgidas nas tutorias ou instrutorias e cujas respostas não tiveram eficácia na busca individual.

A diversidade de oportunidades de aprendizado, associada à perspectiva de fortalecimento da autonomia do discen$t^{27}$, compõe um horizonte altamente propício à formação de um estudante capaz de responder às demandas da sociedade brasileira.

\section{CONSIDERAÇÕES FINAIS}

O MEC, por intermédio das DCN, preconiza a formação de um médico que, além de ser generalista, deve possuir como características uma prática humanizada ${ }^{23}$, crítica e reflexiva, estando capacitado a atuar — pautado em princípios éticos e bioéticos - no processo saúde-doença em seus diferentes níveis de atenção, com ações de promoção, prevenção, recuperação e reabilitação à saúde, visando à integralidade na assistência. Para atingir esses objetivos, é cada vez mais necessário mudar a forma de ensinar-aprender, fazendo com que o aluno deixe de assumir um papel puramente passivo e passe, ele próprio, a construir seu conhecimento com o auxílio dos professores. Essa mudança também permite ampliar os cenários de aprendizagem, que, além da sala de aula, passam a englobar laboratórios específicos, as unidades básicas de saúde e os hospitais, ampliando o contato dos discentes com os pacientes e fazendo-os conhecer, desde o início do curso, as reais condições de saúde no País.

Tal proposição representa uma mudança de paradigma: ultrapassagem de uma educação meramente transmissora, centrada no professor e na transmissão de conhecimentos, para uma metodologia ativa, de inspiração construtivista, centrada no aluno, na qual ele se torna responsável pelo próprio aprendizado. Ademais, por meio de uma modificação na estrutura curricular, as disciplinas passam a ser estudadas de modo integrado umas às outras, permitindo desenvolver uma visão ampliada pelo discente e estabelecer processos de aprendizagem significativa ${ }^{28}$.

Contudo, como toda mudança, esse processo deve ser implantado aos poucos, respeitando as dificuldades que os discentes possam ter devido à imaturidade, inerente a díspares fatores, incluindo a idade, associados à forte presença da metodologia tradicional em sua vida acadêmica até então. Muitas vezes, isto pode levar à incompreensão da filosofia da $\mathrm{ABP}$ e da independência que esses aprendizes adquirem enquanto detentores do seu conhecimento, escolhendo o que querem estudar. Cabe às instituições de ensino superior fornecer a seus discentes todas as informações acerca destas metodologias ativas, de modo a criar com eles uma parceria que seguirá coesa até o fim do curso, fazendo-os se sentir mais seguros e confiantes na instigante aventura de aprender.

\section{REFERÊNCIAS}

1. Brasil. Congresso. Senado. Resolução n. 4 CNE/CES, de 2001. Institui Diretrizes Curriculares Nacionais do Curso de Graduação em Medicina. Diário Oficial da União. Brasília, 9 de nov. 2001; Seção 1, p. 38.

2. Freire P. Pedagogia da esperança: um reencontro com a pedagogia do oprimido. Rio de Janeiro: Paz e Terra, 1999.

3. Feuerwerker L. Além do discurso de mudança na educação médica. São Paulo: Hucitec, 2002.

4. Netto Cezar PH. Mudança de paradigma na educação médica: a introdução de metodologias ativas. In: Moço ETSM, Falcão HBPT, Miranda JFA. Reflexões sobre as Mudanças Curriculares na Área de Saúde: Ativando Processos. Rio de Janeiro: Publit, v. 2, p. 35-53, 2007.

5. Hager P, Gonczi A. What is competence? Med Teac. 2006;18(1):15-18.

6. Mitre MS, Siqueira-Batista R, Girardi-de-Mendonça JM, Morais-Pinto NM, Meirelles CAB, Pinto-Porto $C$, et al. Metodologias ativas de ensino-aprendizagem na formação profissional em saúde: debates atuais. Ciên Saúde Colet. 2008;13(2):2133-2144.

7. Cotta RMM, Gomes AP, Maia TM, Magalhães KA, Marques ES, Siqueira-Batista, et al. Injustiça e desigualdade social: repensando a formação de profissionais de saúde. Rev Bras Educ Med. 2007;31(3):278-286.

8. Siqueira-Batista R, Rôças G, Gomes AP, Albuquerque VS, Araújo F, Messeder JC. Ecologia na formação do profissional de saúde: promoção do exercício da cidadania e reflexão crítica comprometida com a existência. Rev Bras Edu Med. 2009;33(2):271-5.

9. Albuquerque VS, Tanji S, Gomes AP, Siqueira-Batista, R. Pressupostos da construção de um novo currículo para o curso de enfermagem. Rev. Enferm. UFPE on line. 2008;2(3):297-403.

10. Ferreira JR. PROMED: da utopia à realidade. Boletim ABEM.2002;30(6):6-8.

11. Costa HOG. O processo de construção e de trabalho da Rede Unida. Divulg Saúde Debate. 2000;22:9-17. 
12. Coll C. Psicologia e currículo: uma aproximação psicopedagógica à elaboração do currículo escolar. São Paulo: Áttica, 2000.

13. Gomes AP, Siqueira-Batista R, Siqueira-Batista R, Costa CRBSF, Silva Santos S. A formação médica - revisitando Paulo Freire. XLII Congresso Brasileiro de Educação Médica, Vitória. Revista Digital de Educação Permanente em Saúde 2004;1:(suppl.2):236.

14. Berbel N.A. A problematização e a aprendizagem baseada em problemas: diferentes termos ou diferentes caminhos? Interface Comun.Saúde Educ. 1998;2(2):139-154.

15. FESO. Fundação Educacional Serra dos Órgãos: projeto de mudança curricular no curso de graduação em medicina. Teresópolis: FESO, 2002. (mimeografado)

16. Siqueira-Batista R, Siqueira-Batista R. Os anéis da serpente: a aprendizagem baseada em problemas e as sociedades de controle. Ciênc Saúde Colet. 2009;14:1183-92.

17. Bordenave JD, Pereira AM. Estratégias de Ensino-Aprendizagem. Rio de Janeiro: Vozes, 2004.

18. Gomes AP. Olhando o sistema de avaliação discente com os óculos da mudança: aprender a ver, aprender a avaliar. In: Moço ETSM, Falcão HBPT, Miranda JFA. Reflexões Sobre as Mudanças Curriculares na Área de Saúde: ativando Processos. Rio de Janeiro: Publit, 2007. v. 1, p.13-37,

19. Oliveira GS, Koifmamm L. Integralidade do currículo de medicina: inovar / transformar, um desafio para o processo de formação. In: Marins JJJ, Rego S, Lampert JB, Araújo JGC. Educação Médica em Transformação: Instrumentos para a Construção de Novas Realidades. São Paulo: HUCITEC, 2004. p.143-164.

20. Komatsu RS. Guia do processo de ensino-aprendizagem "aprender a aprender". 4. ed. Marília: Faculdade de Medicina de Marília,2003. p.3-35.

21. Lima GZ, Linhares REC. Escrever bons problemas. Rev Bras Edu Med 2008; 32(2): 197-201.

22. Sakai MH, Lima GZ. PBL: uma visão geral do método. Olho Mágico. 1996;2(5/6):1-4.

23. Rego S, Gomes AP, Siqueira-Batista R. Bioética e humanização como temas transversais na formação médica. Rev Bras Educ Med. 2008;32:482-491.
24. Siqueira-Batista R, Rôças G, Gomes AP, Cotta RMM, Messeder JC; Mattos EA. A bioética ambiental e a ecologia profunda são paradigmas para se pensar o século XXI? Ensino, Saúde e Ambiente. 2009,2(2):44-51.

25. Botti SHO, Rego S. Preceptor, supervisor, tutor e mentor: quais são seus papéis? Rev Bras Educ Med. 2008;32(3):363373.

26. Silva SS. Laboratório de habilidades no ensino médico. In: Marins JJ, Rego S, Lampert JB, Araújo JGC. Educação Médica em Transformação: instrumentos para a Construção de Novas Realidades. São Paulo: Hucitec, 2004. p.62-96.

27. Costa CRBSF, Siqueira-Batista R. As teorias do desenvolvimento moral e o ensino médico: uma reflexão pedagógica centrada na autonomia do educando. Rev Bras Educ Med. 2004; 28(3):185-288.

28. Gomes AP, Dias Coelho UC, Cavalheiro PO, Gonçalvez CAN, Rôças G, Siqueira-Batista R. A Educação Médica entre mapas e âncoras: a aprendizagem significativa de David Ausubel, em busca da Arca Perdida. Rev Bras Educ Med. 2008;32(1):105-111.

\section{CONTRIBUIÇÃO DOS AUTORES}

Pedro Henrique Netto Cezar e Francisco Tavares Guimarães elaboraram a primeira versão do presente manuscrito, a qual foi revista por Andréia Patrícia Gomes, Giselle Rôças e Rodrigo Siqueira-Batista

\section{CONFLITO DE INTERESSES}

Declarou não haver.

\section{ENDEREÇO PARA CORRESPONDÊNCIA}

Pedro Henrique Netto Cezar

Centro Universitário Serra dos Órgãos

Av. Alberto Torres, 111

Alto - Teresópolis

CEP 25964-004 - RJ

E-mail: pedrohnc@uol.com.br 